\title{
Significance of Plant Growth Regulators (PGR's) on the Growth and Yield of Wheat Crop
}

\author{
Muhammad Nasir ${ }^{1, ~}$, Muhammad Ameen Ahmad ${ }^{2}$, Shabbir Hussain ${ }^{2}$, Muhammad Ismaeel ${ }^{3}$ \\ ${ }^{1}$ Department of Biochemistry, Government College University, Faisalabad, Pakistan \\ ${ }^{2}$ Departments of Chemistry, Lahore Garrison University, Lahore, Pakistan \\ ${ }^{3}$ Departments of Chemistry, Government College University, Lahore, Pakistan
}

Email address:

m.nasirjaved193@gmail.com (M. Nasir)

${ }^{*}$ Corresponding author

\section{To cite this article:}

Muhammad Nasir, Muhammad Ameen Ahmad, Shabbir Hussain, Muhammad Ismaeel. Significance of Plant Growth Regulators (PGR's) on the Growth and Yield of Wheat Crop. Science Journal of Chemistry. Vol. 7, No. 5, 2019, pp. 98-104. doi: 10.11648/j.sjc.20190705.12

Received: March 18, 2019; Accepted: May 16, 2019; Published: November 21, 2019

\begin{abstract}
The current studies reveal the effect of a plant growth regulator (PGRs) on growth and yield performance of wheat crop. It was demonstrated that plant morphology, physiology, biochemistry and yield of wheat crop is highly effected/ stimulated by the use of low/ different concentration of growth regulators. Various filed experiments were conducted to investigate the effect of concentrations and formulations of three PGR salts (ortho-nitrophenolate, para-nitrophenolate and Sodium-5-Nitroguaiacolate). Various compositions of PGRs were applied as foliar application during different stages of plant growth. Control measurements were also carried out simultaneously using water only. A significant increase in plant height, stem growth, leaf development, chlorophyll contents and other biochemical contents of plant has been observed by the use of PGR. The results indicate that the PGR concentrations of $100 \mathrm{ppm}$ and $150 \mathrm{ppm}$ were found to give the best results. From the current study, it was suggested that dose concentration ranging from100ppm to $150 \mathrm{ppm}$ has momentous potential on plant growth and yield of wheat crop. Also it enhances the nutritional value of crop and reduces the economic cost of former.
\end{abstract}

Keywords: Wheat, Composition, PGRs, Economically Cost, Yield of Crop

\section{Introduction}

Wheat (Triticum aestiyun L.) is one of the important grain crops in Pakistan and is being grown on an area of 8 million Hectare with a total production of 18.2 mat per annum. [1] In general, the wheat yields remain low for public demand and significant amounts of foreign exchange have to be spent on imports. It is needed therefore to look for measures that will lead to enhance wheat yields. Like other living organism, the growth of wheat is under the control of different hormones or plant growth regulators (PGRs) optimum quantities of which may or may not be produced. The use of exogenous hormones has therefore found utility in increasing crop production particularly in developing countries. These substances do not become part of the living cell but have an amazing effect on the plant growth.[2] Among different PGRs, Nitro-phenol (Phenol derivatives) is very effective for Plant physiology and metabolism. Plant Growth Regulators
(PGRs) can regulate plant growth and development in numerous ways. PGRs have potential to modify cereal yield and plant stand structure additional to stem elongation. [2] Plant hormones are chemical stimulants that regulate the plant growth; these are the molecules that stimulate within the plant, and occur in extremely low concentrations. PGRs are the organic compounds, other than nutrients that stimulate the plant physiological process, they are the bio stimulants that stimulate or inhibit the specific enzymes which help to regulate or enhance the plant metabolism process [3].

Normally PGRs are active at very low concentrations, the study of PGRs were recognized in 1930, where some natural and synthetic compounds were introduced that alter the function, size and shape of the crop plants [4]. The current study of PGRs revealed the effects on yield; also play a vital to role as preventing the lodging of crop, preventing the preharvest fruit drop, hastening maturity to decrease the 
turnover time. The plant hormone are essential in the diet as they provide the mineral elements, plant fiber, carbohydrates and proteins [5]. It is also noticed that different PGR, s are very useful as preservative in drinking and beverages [6]. The effective study of PGRs indicates that they enhances the plants physiological and biochemical process, these biochemical process including as dormancy control, size of organ, leaf development with the increase of flowering and fruit, it is also reported that PGRs enhances the uptake concentration of mineral chemicals nutrients which are present in soil cluster [7]. The different growth hormones as indole acetic acid, gibberellin promotes seedling growth [8], when a composition is applied in different concentration, unlike these seedling growth a class of PGRs as Nitrophenol salts (NPs) influences the plant growth and yield of crop like wheat, maize and rice even at very low concentrations as foliar applications [9].

In agriculture countries like India and Pakistan where about 45 million hectares of land is under cultivation and over $70 \%$ of population lives in rural areas, the majority is belong to farming communities. The soil, climate and topography varies from area to area and due to the increase of population there is a need to cultivate the maximum crop to complement the desired need of population, so intensive and multiple cropping practice is adopted recent last 50 years but still we have less yield as per need. The salinization of the soil and deficit of water are the major challenges in Asian countries. On an average $6 \%$ of the world's land and almost $20 \%$ of the world irrigated land are reported which are currently affected by salinity [10]. This increase level of salinity creates toxic growth conditions for most plants, including major crops as wheat and rice, is reported from the study that $\mathrm{NaCl}$ toxicity is largely attributed to the effect of $\mathrm{Na}^{+}$and mannerly with $\mathrm{Cl}^{-}$and that sodium toxicity is linked strongly with the plant's ability to sustain their physiological process [11]. The osmotic stress is caused due to excess of these ions in the soil which accumulates in the plants cell and effects the physiological status of plants $[12,13]$. This ionic stress can be controlled with phytohormones that play an essential role for regulating plant growth. Cytokinins (CSks) and nitrophenol salts (NPs) have been reported for many development process including leaf sequences, apical dominance, chloroplast and regulation of cell division [14]. Water deficit period is also a major challenge for agriculture areas that majorly effect the wheat grain yield and quality of the crop particularly the period of stem elongation and early ripening, water decreases the crops growth of plant by influencing the biological and physiological process such as photosynthesis, respiration, metabolism of nutrients etc.[15]. Plant growth regulators are commonly employed in different crops in Europe and New Zealand where the main input of the PGRs is the prevention of crop lodging by different experimental data and inconsistent results, the crop height is significantly reduced by using the growth hormones, and interaction on wheat grain yield quality in the without lodging [16].

\section{Material and Methods}

The wheat seeds variety "Faisalabad 2008" approved by Punjab Seed Corporation (PSC) was used.

\subsection{Climate and Soil}

The ideal temperature requirement depends upon the plant variety and stage of growth. We provided the following mean daily temperature for during the plant growth and development stages: 20 to $25^{\circ} \mathrm{C}$ during germination, 16 to $20^{\circ} \mathrm{C}$ during tillering, 20 to $23^{\circ} \mathrm{C}$ during accelerated growth stage and 23 to $25^{\circ} \mathrm{C}$ at Proper grain filling stage. Wheat plants are sensitive to very cold or frost injury at any stage of growth particularly at reproductive growth if temperature is below $15^{\circ} \mathrm{C}$. All types of soils are not suitable for wheat sowing. The normal soils with slit clay loam or lighter soil texture, well drained and with no salinity/ sodicity were selected for wheat sowing. Precautions for soil for experiment were measured carefully as EC, $\mathrm{pH}$ and salinity of soil. The salinity of soil was recorded $2.1 \mathrm{dS} / \mathrm{m}$ and $\mathrm{pH}$ of 8.1 with Oahu's instruments by composite sampling of soil; the seeds were washed with de-ionized water before sowing for experiment.

The studies were performed in Lahore District which is located between longitudes $31.5204^{\circ}$ North's and $74.3587^{\circ}$ East's in Punjab (Pakistan). The area under study ranges from nearly level to very gently sloping terrain with mean sea level of $217 \mathrm{~m}$; there is very hot spell in summer with mean maximum temperature of around $37^{\circ} \mathrm{C}$. The average rain fall is $628.8 \mathrm{~mm}$.

The wheat crop requires a well-pulverized but compact seed bed for good and uniform germination. Three or four ploughings in the summer and repeated harrowing in the rainy season followed by planking immediately before sowing produce a good, firm seed bed for the dry crop on alluvial soils. For the irrigated crop, the land is given a presowing irrigation (palewa or raund) and the number of ploughings is reduced.

\subsection{Planting of Seeds}

The variety of wheat seed Faisalabad (2008) was sown in plastic trays containing defined characteristics of soil. The soil defined for this experiment was dried, ground well and sieved ( $\geq 2 \mathrm{~mm}$ ). The optimum water quantity was applied to wheat for reducing water losses having EC (Electrical conductivity) less than one $1000 \mathrm{ppm}$. The excess water caused lodging of crop at maturity time. Wheat crop needs 3 to 4 irrigations from sowing to maturity periods. First irrigation was made after 21 days of sowing and it must not be delayed beyond 21 days, which may cause poor root development. Whereas, subsequent irrigations were applied according to three weeks interval or critical growth stages such as crown root initiation, tillering, flowering and grain filling. The special attention was made on these critical stages for the timely supply of irrigation for achieving the proper growth, and maturity of the plant. After 21 days of germination the average healthy plants were transferred to 
plastic pots, of $(40 \times 40 \mathrm{~cm})$ which contained approximately $10 \mathrm{~kg}$ soil and the same experiment was conducted in one meter square area, the soil for both the experiments was collected from Sayban Research Farm Punjab Lahore and all the experiments were performed at the same Research Farm. Each experiment was performed on five plants and on one square meter area. The whole experiment was conducted at Sayban Research Farm at the time of end November 2016. The experiment was repeated in the same era in year 2017 for wheat season. The recommended fertilizers were applied for experiment in the form of urea, di-ammonium phosphate (DAP), sulfate of potash (SOP) at the time of sowing while nitrogen fertilizers were applied at irrigation time.

\subsection{Composition of Growth Regulators}

Composition of ortho, para-nitrophenolate and sodium-5nitroguaiacolate $(5 \mathrm{NG})$ with ratios of $(3: 2: 1)$ and $1.50 \%(\mathrm{w} /$ v) was made in water. Three different compositions i. e., 100 ppm, $150 \mathrm{ppm}$ and $200 \mathrm{ppm}$ were used; first application was applied as foliar spray after four week of germination and the other two applications were performed during tiller formation and spike initiation, respectively. The control wheat plants were also sprayed with 3 doses of blank as water on the same intervals as PGRs applied on treatments $T 1, T_{2}$ and $T_{3}$ respectively.

\subsection{Effect of Growth Regulators (PGR, s) on Vegetative Growth and Mineral Elements Content}

At the time of harvesting the treated and control samples were collected, the observation was made that the growth regulators enhances the plant height, stem growth and No. of tillers as compared to control plants. The number of leaves and spike length were also measured with meter rule. The effective understanding was made by considering the mineral contents, for this five gram of both treated as well as control samples were used to determine the mineral contents such as Zinc, Iron, Copper, Manganese, Phosphorous, Magnesium, Potassium and sodium. These elements were analyzed with different techniques as Atomic Absorption Spectrophotometer (Model AA-7000), Visible Spectrophotometer (Model-722N) and micro-Kjeldahls method.

\section{Results and Discussions}

Significant increase was monitored in all parameters of wheat experiment with the foliar applications of a mix composition of plant growth regulators. The treatments T1 and $T_{2}$ in Table 1 having concentrations (100 ppm and 150 ppm) were resulted in greater the plant height, No. of tillers, spike length and No. of grain per spike as compared to blank treatment $T_{0}$. The experimental data in Table 1 (Figure 1) was shown that treatment T3 of $200 \mathrm{ppm}$ mix PGR, s was not given remarkable results as T1 and T2. No. of tillers/ 5 plants in both treatments $\mathrm{T} 1$ and T2 were counted (39) and (41) respectively as compared to blank treatment which was of (30) count. The doses $100 \mathrm{ppm}$ and $150 \mathrm{ppm}$ were also increased the spike length as compared to control treatment respectively. Similar increase was monitored in No. of grains per spike as $18 \%$ and $28 \%$ vs. blank in shown Table 1.

Furthermore the experiment was expanded at same time in one meter square area and the data collected from this experiment was shown in Table 2. The additional parameter of biomass weight was studied in this experiment. It was extensively resulted that the application of mix PGRs has also remarkable effects on biomass of the plants as well as the yield of wheat. The biomass in one square meter in Table 2 was $2030 \mathrm{~g}, 2335 \mathrm{~g}$ and $2035 \mathrm{~g}$ respectively in treatments $\mathrm{T} 1, \mathrm{~T} 2$ and $\mathrm{T} 3$. The increment in grain yield in 1 meter square was monitored as $(26.5 \%)$ and $(31 \%)$ in treatments $\mathrm{T} 1$ and T2 respectively from control as shown in (Figure 2). Highest difference recorded in grain yield parameter between untreated and treated plants, these results suggested that growth regulators especially a mix composition of three PGRs increases the physiological rate as well as the productivity of the crop [16]. The hormonal treatments stimulated significant increase in No. of tillers, spike length, biomass and grain yield of the plants when composition was sprayed [17]. Nutrients concentrations in plant were increased slightly by applying growth regulators in various filed trials that suggested that physiological rate of plants were increased by using these PGRs [18].

Table 1. Effect of composition plant growth regulators on plant height, No. of tillers, spike length and No. of grains/ spike on (5-Plants).

\begin{tabular}{llllll}
\hline Treatments & Concentrations $(\mathbf{p p m})$ & Plant height $\mathbf{( c m )}$ & No. of Tiller 5-plant & Spike length (cm) & No. of Grains/ spike \\
\hline T0 & Control & 97 & 30 & 13 & 50 \\
T1 & 111 & 39 & 17 & 61 \\
T2 & 100 & 41 & 18 & 64 \\
T3 & 150 & 120 & 37 & 17 & 60 \\
CV $(\%)$ & 200 & 0.086635 & 0.130262 & 0.136453 & 0.10342 \\
\hline
\end{tabular}

Table 2. Effect of composition plant growth regulators on biomass weight, grain weight in (1 meter square).

\begin{tabular}{lllll}
\hline Treatments & Concentrations (ppm) & Biomass Wt. (g) & Grain Wt. (g) & \% Increase Grain Wt. Vs. Control \\
\hline T0 & Control & 1823 & 448 & - \\
T1 & 100 & 2030 & 567 & 26.5 \\
T2 & 2335 & 610 & 31 \\
T3 & 150 & 2035 & 560 & 25 \\
CV $(\%)$ & 200 & 0.102517353 & 0.126553243 & 0.699927659 \\
\hline
\end{tabular}


The statistical data arranged as without PGRs application the output of wheat crop in one acre is $1792 \mathrm{~kg}$ along with all recommended fertilizers of NPK, but there is a good agreement that crop responded an appreciable increase of yield while using a minute quantities of mix PGRs as shown in Table 2 the yield received through experiment from application of treatments T1 and T2 are $2268 \mathrm{~kg}$ and $2440 \mathrm{~kg}$ respectively. In Table 1 individual segments investigated that PGRs treatment play a vital role by increasing the plant height, No. of tillers, spike length and number of grains per spike as compared to control treatment T0. This indicated that physiological process of the plant also increased by using of plant growth regulators [19]. The treatment T3 having of high dose 200 ppm was given a yield of approximately T1 and T2 in above both Tables $1 \& 2$, in all aspects this was determined that high dose of PGRs will affect that lodging that crop and simultaneously will increase the overheads of crop expenses. A strong observation was made from experiment that the shrinkage of wheat grains was noticed in treatment T0 while the treated plants have healthy grains with mass effect. Biomass of treated and controlled samples was also investigated very keenly as shown in Table 2. Plant growth regulators also have a strong effect on biomass of the plants which indicated the physiological process of the crop.

Table 3. Experimental data of mix PGRs on plant height ( $\mathrm{cm}$ ) in different replications of 5 plants.

\begin{tabular}{llllll}
\hline Treatments & Concentrations (ppm) & R1 & R2 & R3 & Mean Avg. \\
\hline T0 & Control & 95 & 98 & 96 & 111 \\
T1 & 100 & 112 & 109 & 115 & 110.66 \\
T2 & 150 & 114 & 112 & 113.66 \\
T3 & 200 & 105 & 107 & 105 & 0.073 .66 \\
CV $(\%)$ & 0.75903339 & 0.080590881 & 0.056598 & 0.07118639 \\
\hline
\end{tabular}

Table 4. Experimental data of mix PGRs on No. of tillers in different replications of 5 plants.

\begin{tabular}{llllll}
\hline Treatments & Concentrations (ppm) & R1 & R2 & R3 & Mean Avg. \\
\hline T0 & Control & 28 & 32 & 31 & 30.33 \\
T1 & 100 & 37 & 41 & 38 & 38.66 \\
T2 & 150 & 45 & 42 & 44 & 43.66 \\
T3 & 36 & 39 & 40 & 38.33 \\
CV $(\%)$ & 0.759033 & 0.190472 & 0.117123 & 0.142198 & 0.146035 \\
\hline
\end{tabular}

Table 5. Experimental data of mix PGRs on Spike length (cm) in different replications of 5 plants.

\begin{tabular}{llllll}
\hline Treatments & Concentrations (ppm) & R1 & R2 & R3 & Mean Avg. \\
\hline T0 & 0.00 & 13.1 & 13.6 & 13.3 & 13.33 \\
T1 & 100 & 15.6 & 15.9 & 16.4 & 15.9 \\
T2 & 150 & 16.2 & 16.4 & 14.8 & 16.17 \\
T3 & 200 & 14.6 & 0.080221 & 14.83 \\
CV (\%) & 0.759033 & 0.091088 & 0.090964 & 0.06533 \\
\hline
\end{tabular}

Table 6. Experimental data of mix PGRs on No. of grains/ spike in different replications.

\begin{tabular}{llllll}
\hline Treatments & Concentrations (ppm) & R1 & R2 & R3 & Mean Avg. \\
\hline T0 & Control & 52 & 47 & 50 & 49.66 \\
T1 & 50 & 59 & 62 & 62 & 61 \\
T2 & 64 & 63 & 64 & 63.66 \\
T3 & 150 & 60 & 61 & 58 & 59.66 \\
CV $(\%)$ & 200 & 0.084964 & 0.129516 & 0.105836 & 0.104626 \\
\hline
\end{tabular}

At the same time crop season of wheat the experiment was extended to evaluate the experiment authentication by making the three replications R1, R2, R3 of all parameters such as plant height, No. of tillers, spike length and number of grains/ spike with different PGRs dosage on 5-plants and 1-square meter the experimental result of plant height was shown in (Figure 3). Same changes observed in other parameters against given dogs of PGRs. The experimental results of all said parameter were reported in above Tables
(3-6) and below Tables 7-8 respectively with the comparison of control treatment of each parameter. The increase in grain weight (g) shown in (Figure 4). An appreciable increase was observed by making mean average of replications in all segments of the plants. The treatments T2 and T3 of plant growth regulators in Table 3 and Table 4 of dosage 100 ppm and $150 \mathrm{ppm}$ responded favorable results in all parameters of plants were determined and reported in above Tables (3-6) of Table 3 and Table 4 of 1 meter square area [20].

Table 7. Experimental data of mix PGRs on biomass Wt. (g) in different replications 1 meter square.

\begin{tabular}{llllll}
\hline Treatments & Concentrations (ppm) & R1 & R2 & R3 & Mean Avg. \\
\hline T0 & Control & 1830 & 1850 & 1790 \\
T1 & 100 & 2075 & 2040 & 1823.33 \\
\hline
\end{tabular}




\begin{tabular}{llllll}
\hline Treatments & Concentrations (ppm) & R1 & R2 & R3 & Mean Avg. \\
\hline T2 & 150 & 2425 & 2390 & 2384 & 2399.66 \\
T3 & 200 & 2050 & 2025 & 1969 & 2014 \\
\hline
\end{tabular}

Table 8. Experimental data of mix PGRs on grain Wt. (g) in different replications 1 meter square.

\begin{tabular}{llllll}
\hline Treatments & Concentrations (ppm) & R1 & R2 & R3 & Mean Avg. \\
\hline T0 & Control & 440 & 434 & 465 & 446.33 \\
T1 & 100 & 575 & 555 & 560 & 563.33 \\
T2 & 150 & 695 & 670 & 686 & 683.66 \\
T3 & 200 & 590 & 610 & 588 & 595 \\
CV (\%) & 0.75903339 & 0.181986518 & 0.177141 & 0.158239661 & 0.17146234 \\
\hline
\end{tabular}

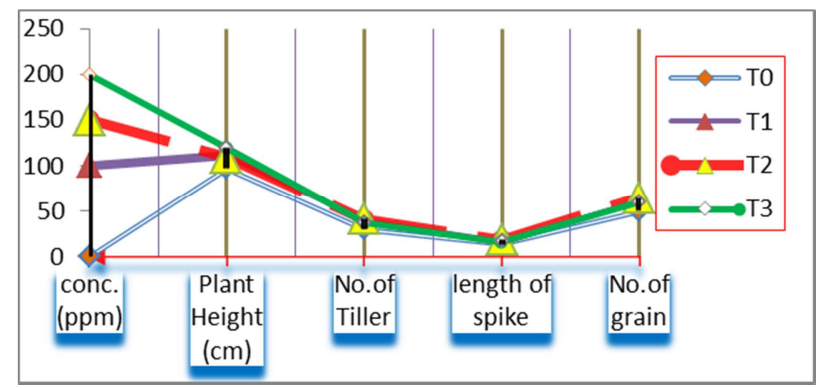

Figure 1. Effect of PGRs concentrations on plant height, No. of tillers, Table 2 .

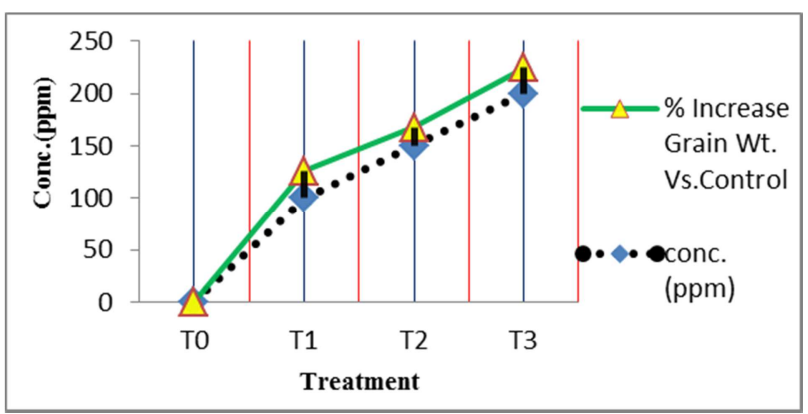

Figure 2. Effect of PGRs concentrations on grain weight \%, spike length and No. of grains/ spike on (5-Plants) Table 1.

\subsection{TOC Graphics}

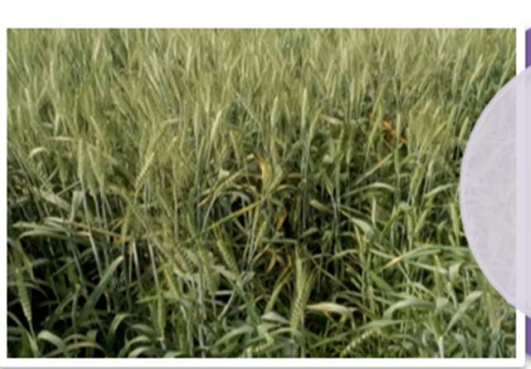

a) Control At maturity Stage

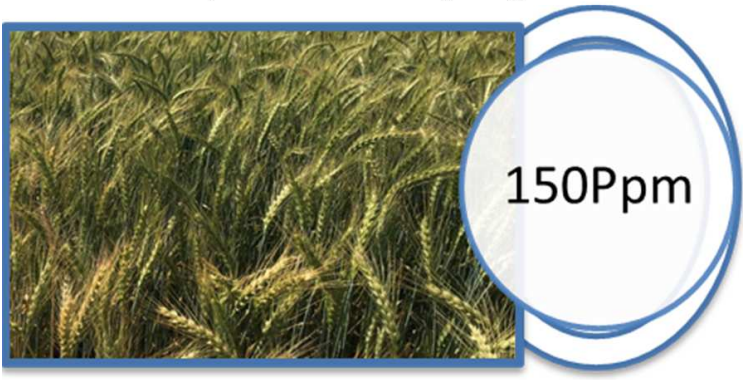

c) $150 \mathrm{Ppm}$

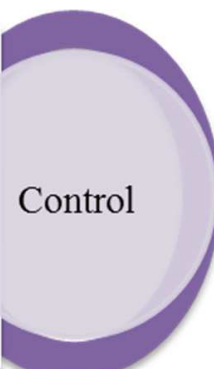

(1)

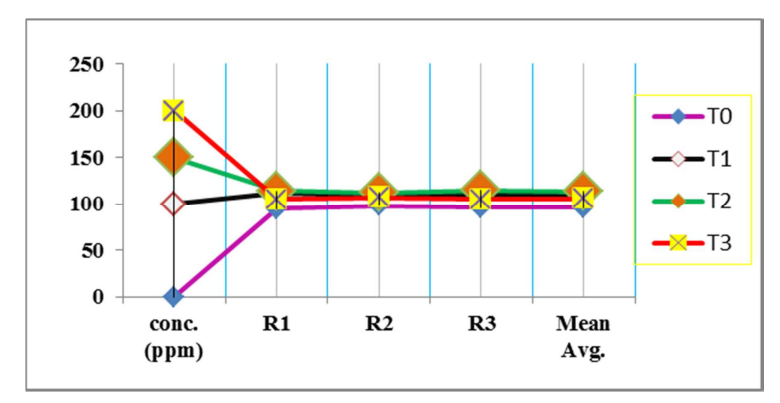

Figure 3. Effect of PGRs concentrations on three replications of different replications 1 meter square Table 3.

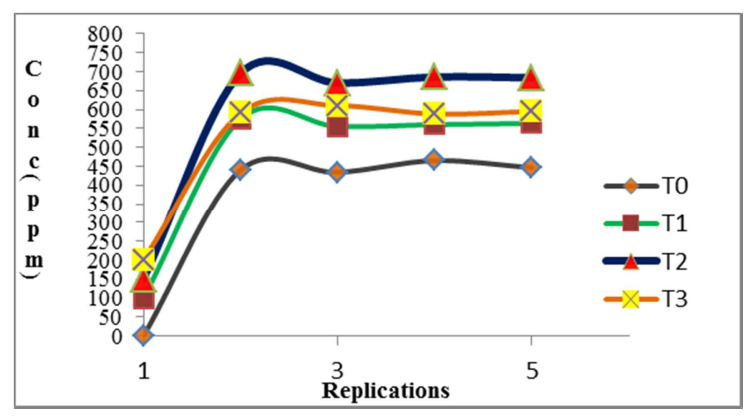

Figure 4. Effect of PGRs concentrations on grain Wt. (g) in plant height (cm) 5-plants and 1-square meter. Table 8.

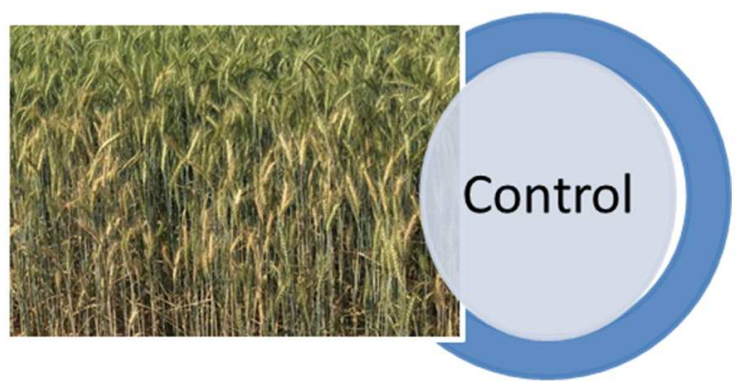

b) Near to Harvasting Stage

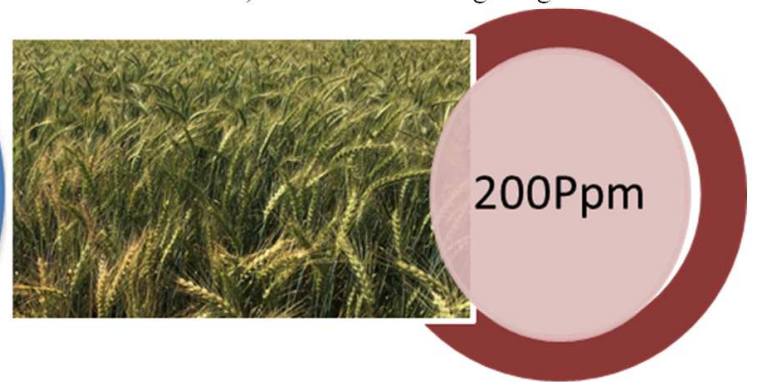

d) $200 \mathrm{Ppm}$ 


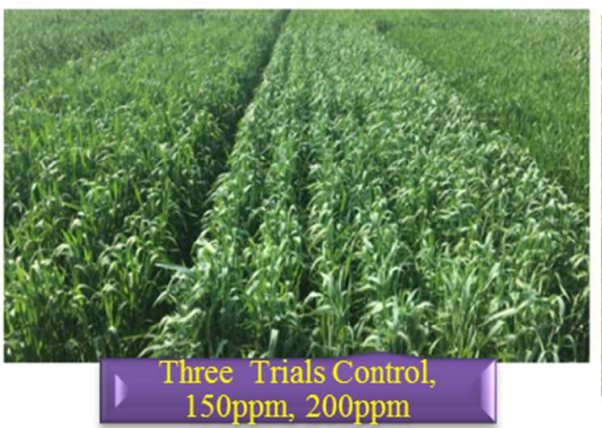

e) Three Trials Control, $150 \mathrm{ppm}, 200 \mathrm{ppm}$

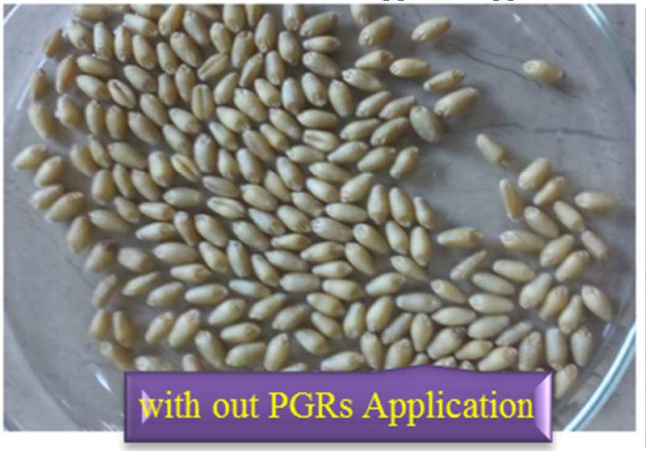

g) with out PGRs Application

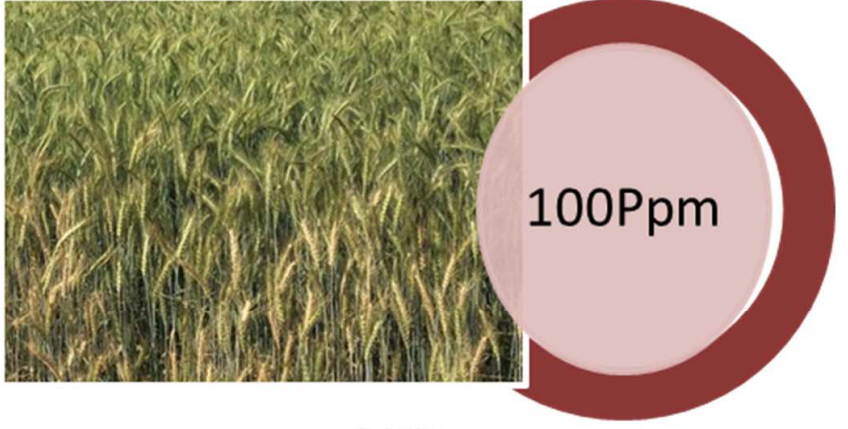

f) $100 \mathrm{Ppm}$

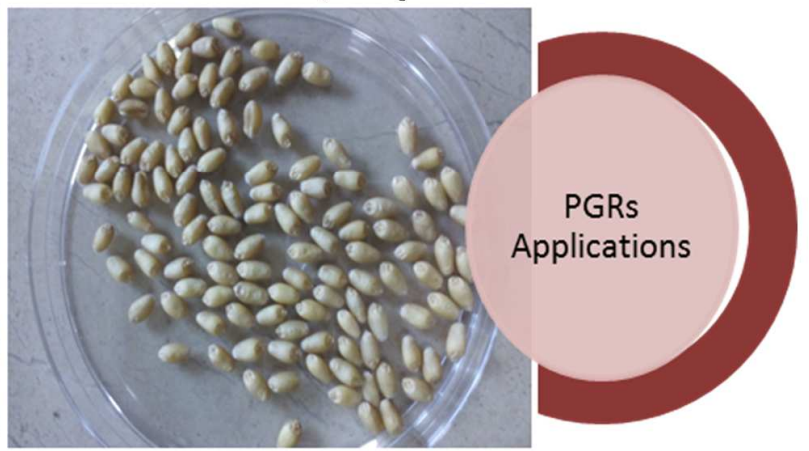

h) PGRs Applications

Figure 5. Show three trial Control, 150ppm and 200ppm from right to left side respectively pictorial views of different PGRs Foliar Application and Control.

\subsection{Significance}

It has been observed that PGRs especially Nitro-phenol promote the protein acceleration in seedling and the soluble sugar was lower. These results proved that sodium 5nitroguaiacolate played an important role in the course of germination of wheat and crop production.

\subsection{Statistically Analysis}

The data were analyzed statistically by applying ANOVA. To find out significant difference among treatment means, stander deviation and coefficient variance (CV). Duncan's Multiple Range Test (Steel \& Torrie, 1986) was also applied.

\subsection{Molecular Impact of Nitro-phenols}

The plant growth regulator consisting of mix composition of nitro-phenols in different treatments stimulated significant increase in the total yield of wheat crop. Different research work has been devoted to identify the enzymes or PGRs that brings the cell division and chlorophyll of plant that increases the fruiting and flowering of crop. Phenolic compound are also able to play a vital role as chain breaker that are strongly oxidative free radicals which ultimately enhance the crop yield [21]. Plant growth regulators including nitro-phenols increases the defense function in plant tissues. It was observed that nitro-phenols treated plant have more activity isoforms of SOD as compared to control plants. The SOD play an important role by protecting the plant cells against the toxic effects of superoxide radicals produced during the process of oxidative burst [22]. It was reported that normal dosage of plant growth regulators were applied on wheat crop and other small grains containing crop that have an important role to prevent the lodging of crop [23]. These PGRs can also be used for the production of sugarcane [24]. As experimented in Table 2 the yield of the crop was increased by applying the plant growth regulators, it was also reported that the PGRs have also a vital role for the reduction of losses and reduction of time duration of production cycle [25]. Studied revealed that nitro-phenol treated plants increase the physiological rate that favored the accumulation of IAA by inhibiting the IAA decarboxylation [26]. Also a strong recommendation have been studied that nitro-phenol maintains the enzyme activity that prevent the increase of cytosolic $\mathrm{H}_{2} \mathrm{O}_{2}$, that create the toxic conditions when accumulated in plant cells by leading oxidative stress to plants [27]. A significant relationship has been observed between leaf development, grain yield by the application of plant growth regulators that earlier has been reported $[28,29]$.

\subsection{Cost \& Production Relationship}

We also ascertain the cost of wheat production and former labor and find out that both parameters reduced by applying PGRs dose as compare to other fertilizer. To estimate the cost of production and to analyze the cost -benefit ratio which was $1: 1.4,1: 1.2$, and $1: 1.3$ in R1, R2, and R3 trials respectively. it is evident that our farmers are not achieving the potential yield. However, in broader sense, it is a possible option that recommendations/ suggestions have been made for the improvement of better yield.

\section{Conclusion}

On the basis of results observed through experiment in this paper, plant growth regulator treatments significantly 
increased the growth, yield and food quality of wheat crop. Treatments of PGRs having dosage of $100 \mathrm{ppm}$ and $150 \mathrm{ppm}$ induced the high yield of crop including the other parameters as plant height, spike length, No. of grains of wheat crop. A strong recommendation have been made through experiment that mix composition of plant growth regulators of $4 \mathrm{~N}, 2 \mathrm{~N}$ and $5 N G$ increased the yield as well as play a key role to enhanced the physiological rate of plant cells by preventing the lodging of crop. Composition \% of PGRs and doses of treatments illustrated the key factor to evaluate the significant results of wheat.

\section{References}

[1] Islam, S., et al., GROWTH AND YIELD OF WHEAT AS INFLUENCED BYGA3 CONCENTRATIONS.

[2] Espindula, M., et al., Use of growth retardants in wheat. Planta Daninha, 2009. 27 (2): p. 379-387.

[3] Gausman, H., et al. Effects of 1, 1 dimethyl-piperidinium chloride on cotton (Gossypium hirsutum L.) leaf chlorophyll, size, and structure. in Proceedings of the Plant Growth Regulator Working Group; annual meeting. Plant Growth Regulator Working Group (USA). 1978.

[4] Jung, J. and W. Rademacher, Plant growth regulating chemicals-cereal plant. Plant growth regolting chemical. CRC press. Inc. PP, 1983: p. 254-271.

[5] Hollingswortn, D., The place of potatoes and other vegetables in the diet. Vegetable Productivity. Macmillan London, 1981: p. 6-13.

[6] Mukhtar, F., Effect of some plant growth regulators on the growth and nutritional value of Hibiscus sabdariffa L. (Red sorrel). International Journal of Pure and Applied Sciences, 2008. 2 (3): p. 70-75.

[7] Nickell, L. G., Plant Growth Regulators. Chemical and Engineering News, 1978. 56 (41): p. 18-34.

[8] Mella, R., et al., Quantification of GA3 regulated in RNA abundance in Tomato seeds using tissue printing. Encyclopaedia of Plant Physiology. p, 1997: p. 292-295.

[9] Janick, J., et al., Plant science, an introduction to world crops. Plant science, an introduction to world crops, 1969.

[10] Rhoades, J. D., The use of saline waters for crop production. 1992, FAO.

[11] Tester, M. and R. Davenport, $\mathrm{Na}+$ tolerance and $\mathrm{Na}+$ transport in higher plants. Annals of botany, 2003. 91 (5): p. 503-527.

[12] Lefevre, I., E. Gratia, and S. Lutts, Discrimination between the ionic and osmotic components of salt stress in relation to free polyamine level in rice (Oryza sativa). Plant Science, 2001. 161 (5): p. 943-952.

[13] Ueda, A., et al., Photosynthetic limitations of a halophyte sea aster (Aster tripolium $\mathrm{L}$ ) under water stress and $\mathrm{NaCl}$ stress. Journal of Plant Research, 2003. 116 (1): p. 63-68.
[14] Kaur, J., O. Singh, and N. Arora, Kinetin Like Role of TDZ (Thidiazuron)-in Salinity Amelioration in Wheat (Triticum Aestivum). Journal of Research, 2002. 39 (1): p. 82-84.

[15] Entz, M. and D. Fowler, Critical stress periods affecting productivity of no-till winter wheat in western Canada. Agronomy Journal, 1988. 80 (6): p. 987-992.

[16] Křen, J., et al., Yield and grain quality of spring barley as affected by biomass formation at early growth stages. Plant Soil Environ, 2014. 60 (5): p. 221-227.

[17] Emam, Y. and P. Cartwright, Effects of drying soil and CCC on root: shoot growth and water use in barley plants. Monograph-British Society for Plant Growth Regulation, 1990 (21): p. 389-392.

[18] Maize, I. and W. I. Center, Book of abstracts: Arnel R. Hallauer international symposium on plant breeding. 2003: CIMMYT.

[19] Morgan, P., Synthetic growth regulators: potential for development. Botanical Gazette, 1980. 141 (4): p. 337-346.

[20] Matysik, J., et al., Molecular mechanisms of quenching of reactive oxygen species by proline under stress in plants. Current Science, 2002: p. 525-532.

[21] Grassmann, J., S. Hippeli, and E. F. Elstner, Plant's defence and its benefits for animals and medicine: role of phenolics and terpenoids in avoiding oxygen stress. Plant Physiology and Biochemistry, 2002. 40 (6-8): p. 471-478.

[22] Halliwell, B. and J. M. Gutteridge, Free radicals in biology and medicine. 2015: Oxford University Press, USA.

[23] Wareing, P., Introduction-Modification of plant growth by hormones and other growth regulators. Outlook on Agriculture, 1976.9 (2): p. 42-45.

[24] Nickell, L., Chemical growth regulation in sugar cane. Outlook on Agriculture, 1976. 9 (2): p. 57-61.

[25] Moore, P. Sugarcane growth response to serial applications of gibberellic acid. in Proceedings of the Plant Growth Regulator Working Group; annual meeting. Plant Growth Regulator Working Group. 1978.

[26] Li, X., S. Li, and J. Lin, Effect of GA3 spraying on lignin and auxin contents and the correlated enzyme activities in bayberry (Myrica rubra Bieb.) during flower-bud induction. Plant Science, 2003. 164 (4): p. 549-556.

[27] Srivalli, B. and R. Khanna-Chopra, Induction of new isoforms of superoxide dismutase and catalase enzymes in the flag leaf of wheat during monocarpic senescence. Biochemical and biophysical research communications, 2001. 288 (4): p. 1037-1042.

[28] Stahli, D., et al., Contribution of the wheat (Triticum aestivum L.) flag leaf to grain yield in response to plant growth regulators. Plant growth regulation, 1995. 16 (3): p. 293-297.

[29] Shakirova, F. M., et al., Changes in the hormonal status of wheat seedlings induced by salicylic acid and salinity. Plant science, 2003. 164 (3): p. 317-322. 